02

\title{
Структурные и оптические характеристики синтетических алмазов в нано-, микро- и миллиметровом масштабе
}

\author{
(C) A. Olejniczak ${ }^{1}$, R. Tomala ${ }^{1, *}$, P. Żemojtel ${ }^{1}$, A.F. de Araujo Maia ${ }^{1,2}$, O. Bezkrovnyi ${ }^{1}$, B. Macalik ${ }^{1}$, O. Игнатенко ${ }^{3}$, \\ D. Beben ${ }^{1,2}$, W. Strȩk ${ }^{1}$ \\ ${ }^{1}$ Institute of Low Temperature and Structure Research Polish Academy of Sciences, \\ 50-422 Wrocław, Poland \\ ${ }^{2}$ Nanores Sp. Z o. o. Sp. K., \\ 51-317 Wrocław, Poland \\ ${ }^{3}$ Научно-практический центр Национальной академии наук Беларуси по материаловедению, \\ 220072 Минск, Беларусь \\ * e-mail: r.tomala@intibs.pl
}

Поступила в редакцию 15.07.2021 г.

В окончательной редакции 24.09.2021 г.

Принята к публикации 27.09.2021 г.

Синтетические алмазы являются предметом исследования во многих областях. Распознавание свойств материалов с размерами, близкими к нанометровому масштабу, имеет большое значение для фундаментальной науки и множества различных приложений. В данной работе микроалмазы, синтезированные при высоком давлении и высокой температуре (методом НРНТ), и наноалмазы, полученные детонационным путём, оценивались с помощью методик XRD, SEM, TEM и спектроскопии комбинационного рассеяния света. Были также выполнены измерения люминесценции в видимой и ультрафиолетовой (УФ) областях спектра и сопоставлены друг с другом для оценки влияния поверхностных дефектов и размера зерен на оптические свойства алмазов.

Ключевые слова: алмазы, спектроскопия, дефекты.

DOI: $10.21883 /$ OS.2022.01.51907.39-21

\section{Введение}

Возраст природных алмазов составляет в основном 1-3.3 миллиарда лет, они образовались на глубинах $150-200 \mathrm{~km}$ в верхней литосферной мантии при температурах $1000-1300^{\circ} \mathrm{C}$ и давлении 40-60 kbar [1]. Алмазы встречаются также в местах падения метеоритов [2]. На протяжении веков бриллианты считались дорогостоящим материалом для изготовления украшений, а самые редкие образцы служили символом власти и благородства [3]. Ситуация изменилась в XX веке, когда были разработаны методы производства синтетических алмазов. Первым методом получения синтетического алмаза был синтез при высоком давлении и высокой температуре (НРНТ) [4]. Источник углерода высокой чистоты (графит) нагревают до $1500^{\circ} \mathrm{C}$ при давлении $5 \mathrm{GPa}$. Расплавленные металлы (Fe, $\mathrm{Ni}, \mathrm{Co}$ ) используются для растворения графита и в качестве катализатора для снижения температуры и давления, необходимых для образования алмаза из графита. Во втором методе, а именно, химическом осаждении из паровой фазы (CVD), алмазы выращивают на подложках из смеси углеводородов, в основном метана, и водорода [5]. Метод CVD требует более низких температур $\left(700-1300^{\circ} \mathrm{C}\right)$ и давления (менее $\left.1 \mathrm{~atm}\right)$. Еще один метод использует взрыв для преобразования углеродной подложки в нанокристаллы алмаза, так называемые детонационные наноалмазы [6,7]. Развитие производства синтетических алмазов позволило использовать их в коммерческих целях для огранки и полировки, оптики, электроники или в качестве синтетических драгоценных камней для ювелирных изделий [8-10]. Алмаз как широкозонный материал можно рассматривать как матрицу для оптически активных ионов и центров окраски [11-13]. Алмазные порошки микрометрового размера были недавно исследованы как многообещающий материал для применения в белом освещении [14]. Однако синтетически произведенные алмазы не лишены дефектов, таких как примеси или $s p^{2}$-гибридизированные структурные изменения [15]. Распространенные примеси, связанные с азотом, могут образовывать множественные центры окраски и снижать прозрачность синтезированных алмазов [16,17]. Целью данной работы является исследование синтетических алмазов различных размеров от нанометрового до миллиметрового. Структурные свойства исследуются методами рентгеновской дифракции (XRD) и комбинационного рассеяния, а также электронной микроскопии. Затем в работе исследуются оптические свойства, чтобы проверить влияние различных размеров алмазных зерен на их потенциальные спектроскопические применения. 


\section{Эксперимент}

Методом НРНТ спекания были синтезированы микрокристаллический алмазный порошок $(100 \mu \mathrm{m})$ и алмазная пластина $(2 \mathrm{~mm})$. В качестве катализатора использовался сплав никеля и марганца. Графитовый порошок вместе с катализатором перемешивали в течение 20 часов. Затем реакционную смесь прессовали под давлением $0.2 \mathrm{GPa}$ в цилиндрическую форму диаметром $12 \mathrm{~mm}$ и высотой $10 \mathrm{~mm}$. Порошок наноалмазов был синтезирован путем детонации из твердой смеси различных углеродных материалов, таких как микрографит, углеродная сажа и ультрадисперсный алмаз. В качестве реагента окисления использовали смесь 40\% тротила и $60 \%$ гексогена. Порошки синтетических алмазов с размером зерен около $500 \mathrm{~nm}$ и $1-2 \mu \mathrm{m}$ были закуплены у компании EID Industrial Diamonds (каталожные номера ERD-UM 0-0.50 и ERD-UM 1-2 соответственно). Рентгеновские измерения порошков проводились на дифрактометре PANalytical X'Pert Pro $\left(\mathrm{Cu}_{\mathrm{K} \alpha 1}: 1.54060 \AA\right)$. Измерения комбинационного рассеяния света проводились с использованием спектрометра Renishaw InVia Raman, оснащенного конфокальным оптическим микроскопом DM 2500 Leica и детектором CCD в геометрии обратного рассеяния. Спектры комбинационного рассеяния света регистрировались при возбуждении аргоновым лазером, излучающим на длине волны $514 \mathrm{~nm}$, объективом 20x LWD за одно сканирование с временем экспозиции $20 \mathrm{~s}$ в спектральном диапазоне $100-3300 \mathrm{~cm}^{-1}$. Перед накоплением данных положение пиков комбинационного рассеяния света было откалибровано с использованием эталонного образца кремния в качестве внутреннего стандарта с положением пика $520.3 \mathrm{~cm}^{-1}$. Морфология образцов порошка была охарактеризована с помощью сканирующей электронной микроскопии (SEM) с помощью Helios G4 PFIB CXe DualBeam FIB/SEM, работающего при $2 \mathrm{kV}$ и $0.2 \mathrm{nA}$. Топография алмазной пластины была охарактеризована с помощью атомно-силовой микроскопии (AFM) с использованием NanoSurf FlexAFM в контактном режиме. Измерения с помощью просвечивающей электронной микроскопии (ТЕМ) проводили с помощью микроскопа Philips CM-20 SuperTwin TEM, работающего при $160 \mathrm{kV}$. Спектры поглощения измеряли с помощью спектрофотометра Agilent Cary 5000 UV-VIS-NIR, оснащенного приставкой Praying Mantis фирмы Harrick для измерения в режиме отражения. В качестве эталона использовали порошок $\mathrm{Al}_{2} \mathrm{O}_{3}$ со средним размером зерна $50 \mathrm{~nm}$. Спектры излучения были измерены с помощью спектрометра Stellarnet Silver-Nova и лазерного диода CNI Lasers $266 \mathrm{~nm}$ мощностью $50 \mathrm{~mW}$ в качестве источника возбуждения. Времена затухания люминесценции измеряли с помощью лазера Libra фирмы Coherent (1 mJ, $89 \mathrm{fs})$, оптического параметрического усилителя OPerA-Solo и Streak Camera фирмы Hamamatsu.

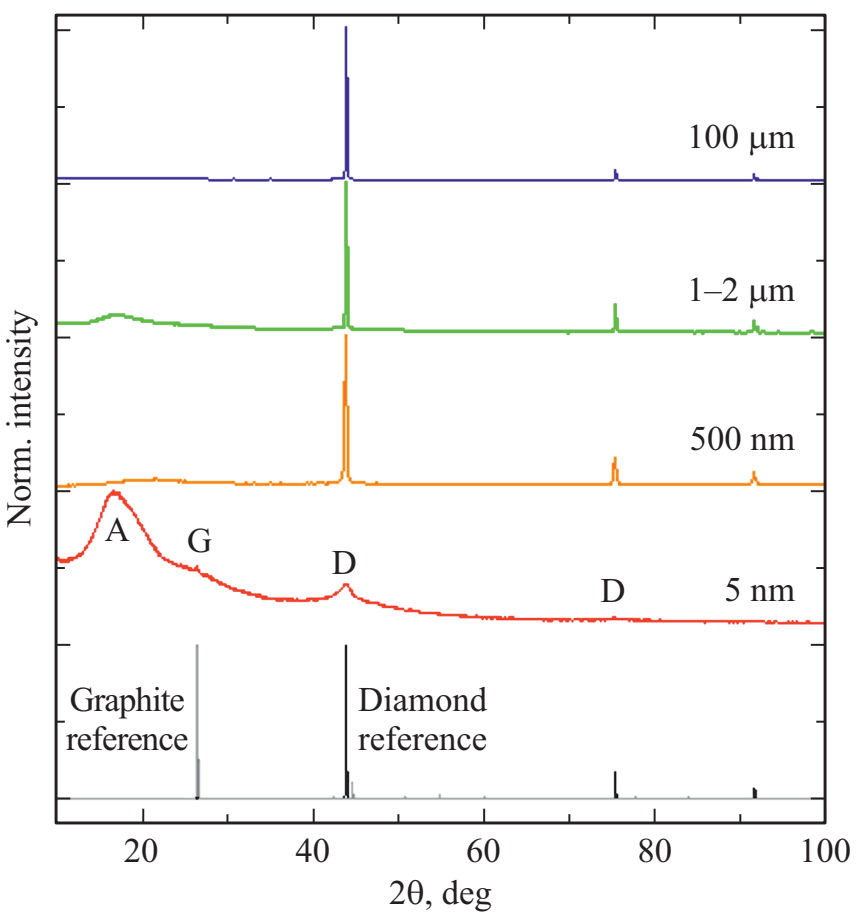

Рис. 1. Порошковые дифрактограммы для исследованных образцов алмазов различных размеров. Для образца наноалмазов указаны отражения от алмазной $(\mathrm{D})$, графитовой $(\mathrm{G})$ и аморфной (А) фаз.

\section{Результаты и обсуждение}

Были исследованы пять образцов алмазов, включая четыре образца порошка со средними размерами зерен $5 \mathrm{~nm}, 500 \mathrm{~nm}, 1-2 \mu \mathrm{m}$ и $100 \mu \mathrm{m}$ и одну квадратную алмазную пластину со стороной $2 \mathrm{~mm}$. Структура порошковых образцов исследовалась методом рентгеновской дифракции (рис. 1). Образец наноалмазов $(5 \mathrm{~nm})$ демонстрирует широкий пик примерно при $17^{\circ}$, обусловленный фазой аморфного углерода [18], и плечо примерно при $26^{\circ}$, являющееся сигналом от графитовой фазы. Можно видеть, что широкий пик, относящийся к аморфной фазе, примерно в пять раз более интенсивен, чем первое отражение (111) алмаза, что указывает на высокий вклад аморфной углеродной фазы в конечную структуру наноалмаза. Остальные порошковые образцы показывают хорошую кристалличность и отсутствие других фаз. Позже морфология синтетических алмазов была исследована методами электронной микроскопии (рис. 2). Самые крупные микроалмазы $(100 \mu \mathrm{m})$ характеризуются превосходной кристалличностью отдельных зерен. Можно выделить большое количество зерен симметричной формы: октаэдры, усеченные октаэдры или кубооктаэдры. Однако присутствуют и более искаженные, сдвоенные и дефектные зерна. При уменьшении среднего размера отдельные зерна становятся более неправильными. Лишь небольшое количество отдельных зерен с высокой симметрией присутствует для образ- 

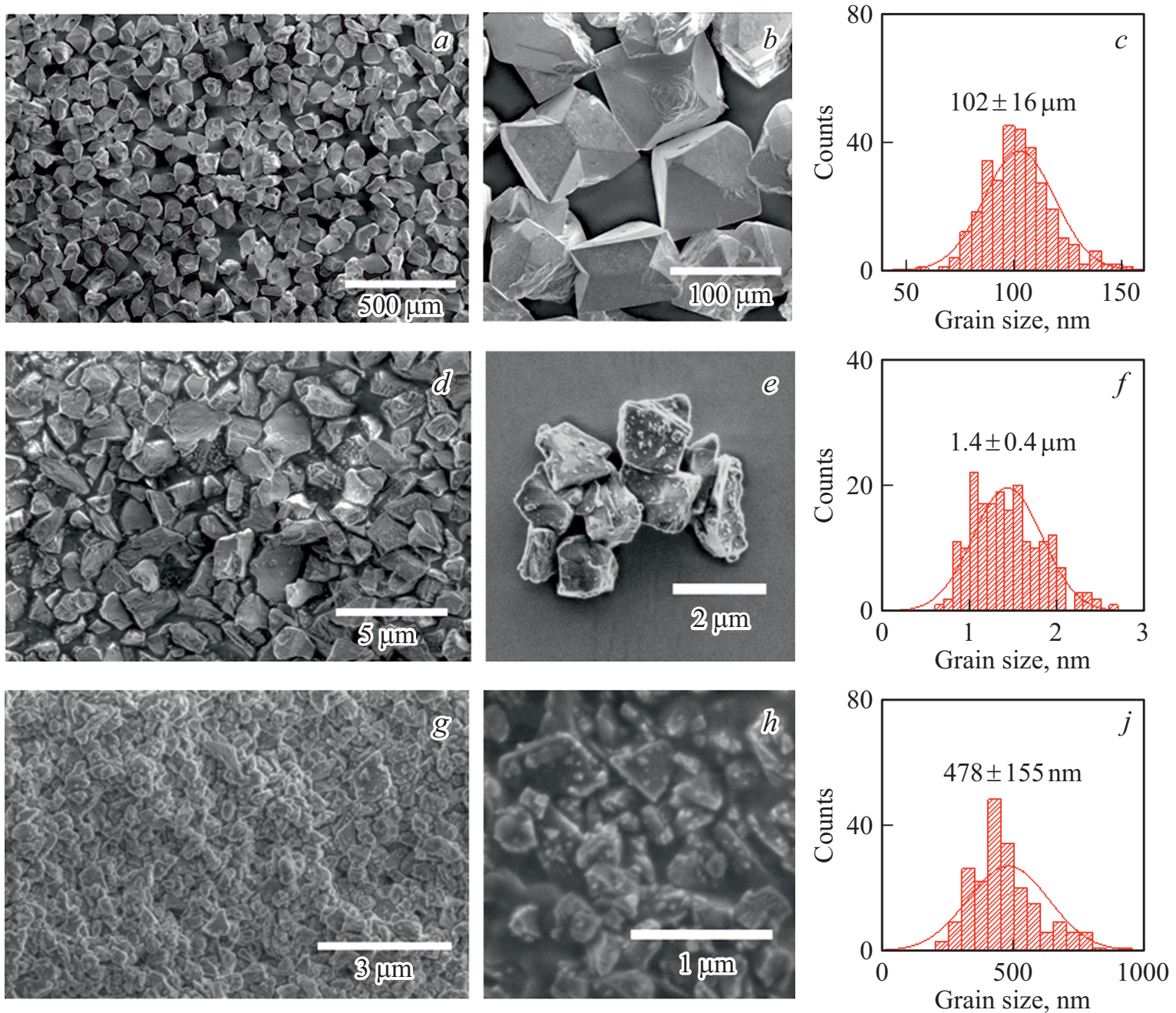

Рис. 2. Репрезентативные изображения $\operatorname{SEM}(a, d, g)$, крупные планы $(b, e, h)$ и гистограммы $(c, f, i)$ образцов порошкового алмаза. Микроалмазы размером $100 \mu \mathrm{m}(a-c)$, микроалмазы размером $1-2 \mu \mathrm{m}(d-f)$ и наноалмазы размером $500 \mathrm{~nm}(g-i)$.

цов $1-2 \mu \mathrm{m}$ и $500 \mathrm{~nm}$. Для образца размером $1-2 \mu \mathrm{m}$ есть зерна с плоской поверхностью, подобные образцу $100 \mu \mathrm{m}$; однако неровности и поверхностные повреждения играют более важную роль в общей морфологии отдельных зерен. Поскольку размер детонационных наноалмазов был слишком мал для получения изображений с помощью SEM, их морфология была исследована с помощью метода ТЕМ (рис. 3). Зерна имеют сферическую форму с высокой склонностью к агломерации. Более того, с уменьшением среднего размера зерен образцы демонстрируют повышенную склонность к агломерации из-за их увеличившейся поверхностной энергии. Кристалличность образца была дополнительно подтверждена дифракцией электронов (рис. $3, c)$. Первоначальное изображение поверхности алмазной пластины на сканирующем электронном микроскопе показало наличие плотно расположенных дефектов в форме квадрата (рис. $4, a)$. Более точная характеризация поверхности пластины с помощью AFM показала, что квадратные де- фекты имеют размер около $100 \mathrm{~nm}$ и глубину $20-40 \mathrm{~nm}$ (рис. $4, b$ ).

Такие дефекты могут служить активными центрами процесса графитизации при нагреве [19] или интенсивном лазерном возбуждении [20]. Для дальнейшего исследования поверхности образцов была использована спектроскопия комбинационного рассеяния света (рис. 5). Полоса $1332 \mathrm{~cm}^{-1}$, характерная для $s p^{3}$-гибридизированной структуры алмаза [21], наблюдалась для всех исследованных образцов. Отношение интенсивности алмазной полосы к фону увеличивается с увеличением размера зерен образца. Однако в образце детонационного наноалмаза алмазная полоса практически не видна из-за значительного вклада аморфного углерода, окружающего $s p^{3}$-гибридизированные ядра отдельных зерен наноалмазов. Это согласуется с выводами, сделанными на основе порошковой XRD наноалмазов, и с предыдущими литературными сообщениями $[18,19]$. Алмазная пластина демонстрирует самую высокую кристалличность среди всех образцов. Это единственный 

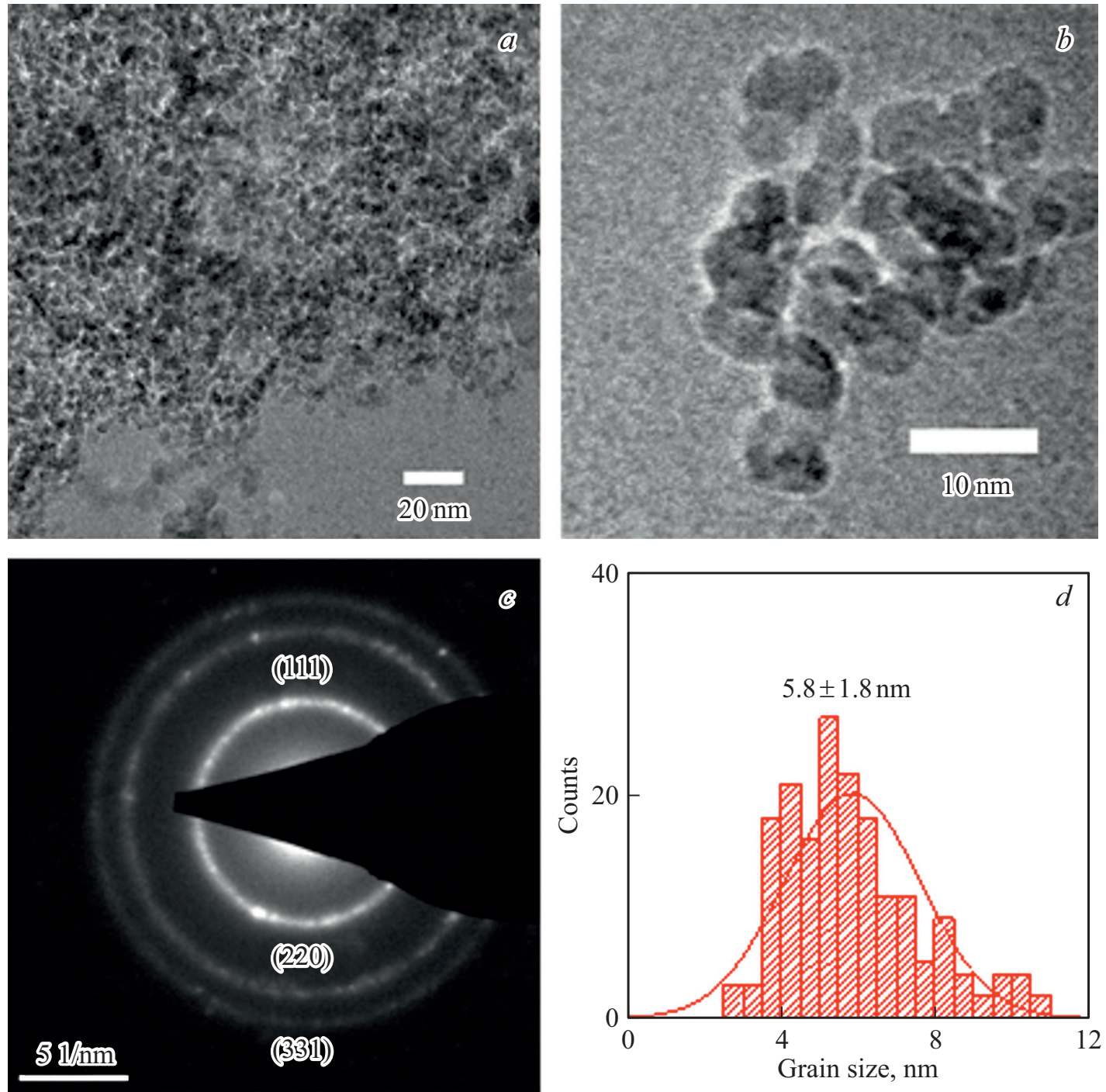

Рис. 3. Типичное изображение ТЕМ $(a)$ и крупный план $(b)$ образца детонационных наноалмазов. Структура алмаза, подтвержденная дифракцией электронов $(c)$. Гистограмма размеров зерен наноалмазов $(d)$.

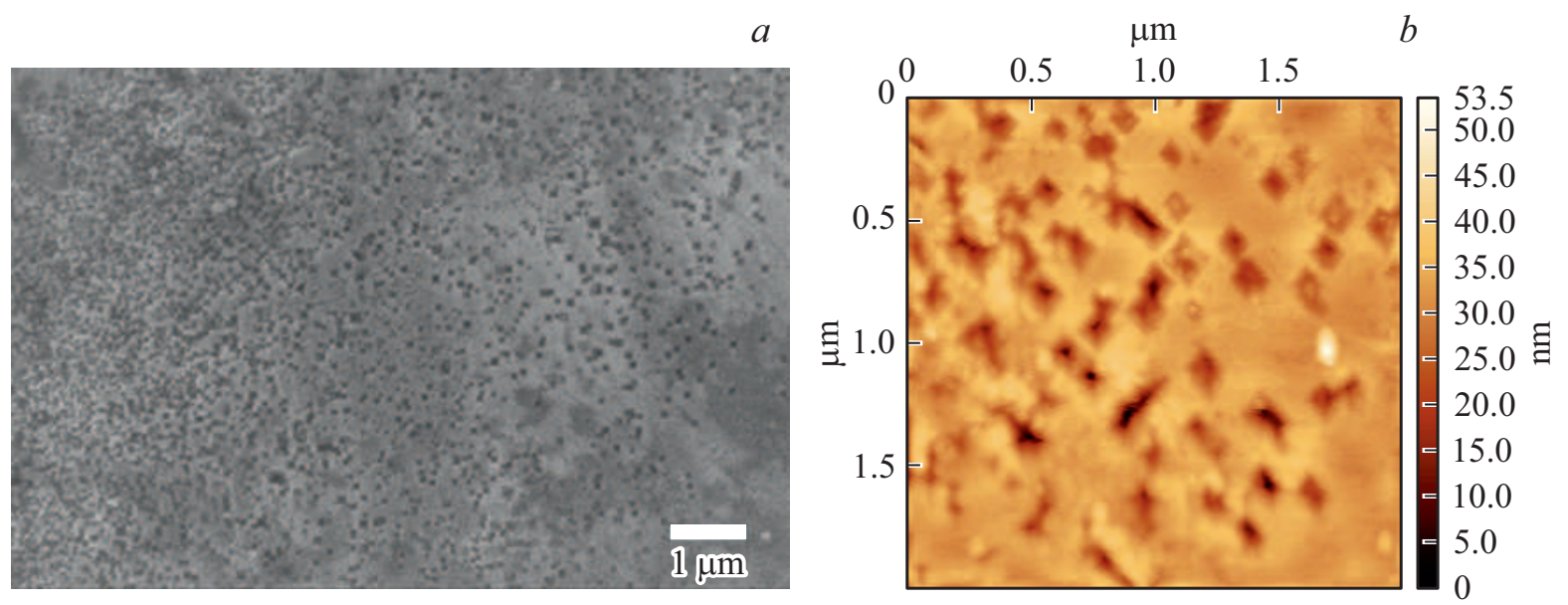

Рис. 4. Типичные изображения алмазной пластины HPHT с помощью SEM $(a)$ и $\operatorname{AFM}(b)$. 


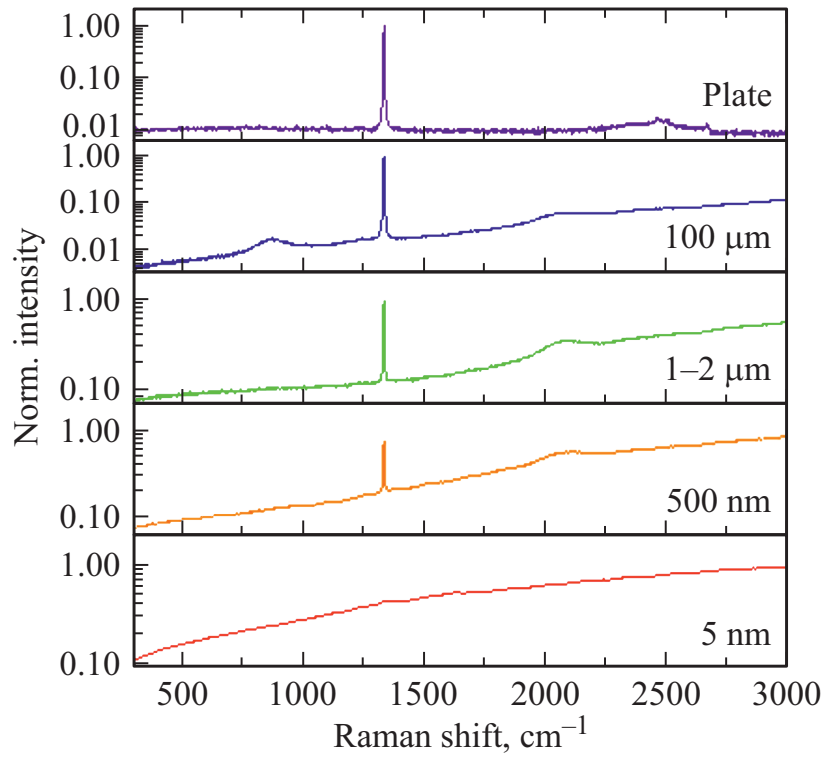

Pис. 5. Спектры комбинационного рассеяния света исследованных образцов алмазов разных размеров.

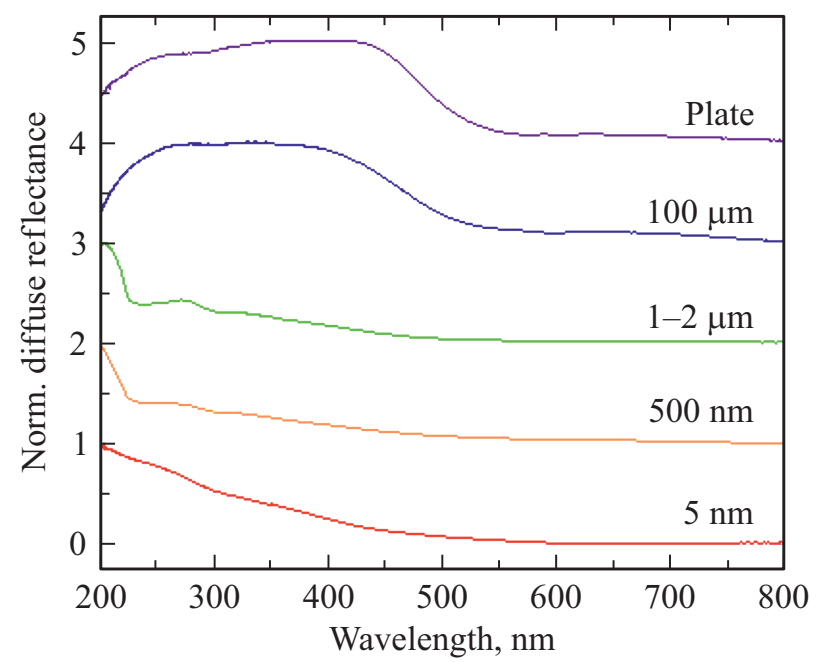

Рис. 6. Спектры диффузного отражения исследованных образцов алмазов в видимом и ближнем УФ диапазоне.

образец, для которого видны полосы комбинационного рассеяния света второго порядка в структуре алмаза $\left(2458 \mathrm{~cm}^{-1}\right.$ и $\left.2667 \mathrm{~cm}^{-1}\right)$ [21].

В остальных порошковых образцах видна широкая полоса с центром около $2100 \mathrm{~cm}^{-1}$, которая может быть связана с примесями азота, образующими центры $\mathrm{NV}^{0}[22]$. В порошковом образце микроалмазов $(100 \mu \mathrm{m})$ наблюдается дополнительная полоса около $865 \mathrm{~cm}^{-1}$, возможно, относящаяся к дефектам, связанным с никелем $[23,24]$ из никель-марганцевого катализатора, используемого в процессе синтеза НРНТ. Можно видеть, что никаких полос, характерных для структуры $s p^{2}$-гибридизированного графита [25] (т.е. полосы D при $1350 \mathrm{~cm}^{-1}$, полосы $\mathrm{G}$ при $1582 \mathrm{~cm}^{-1}$, полосы $\mathrm{G}$ при
$2700 \mathrm{~cm}^{-1}$ ) не наблюдалось. Хотя дефекты поверхности были четко видны во всех образцах при визуализации SEM/AFM, никакой реконструкции поверхности до структуры графита обнаружено не было. Такой результат может быть связан с тем, что поверхностные $s p^{2}$-гибридизированные атомы не образуют типичного расположения, и их отклик в процессе комбинационного рассеяния света затмевается сильным рамановским откликом $s p^{3}$-гибридизированной матрицы. Было замечено, что цвет исследуемых образцов алмаза зависит от размера зерна и метода синтеза. Цвет меняется с темно-серого для образца $5 \mathrm{~nm}$, через белый для образцов $500 \mathrm{~nm}$ и $1-2 \mu \mathrm{m}$ и зеленый для образца $100 \mu \mathrm{m}$ до желтого для алмазной пластины. Это подтверждается измерением диффузного отражения образцов при комнатной температуре (рис. 6). Серый цвет образца $5 \mathrm{~nm}$ возникает из-за смешения кристаллических наноалмазов с аморфным углеродом, который имеет черный цвет. В образцах $500 \mathrm{~nm}$ и $1-2 \mu \mathrm{m}$ нет интенсивных полос до края поглощения, что подтверждается их белым цветом. В отличие от образцов меньшего размера, микроалмазы и алмазная пластина демонстрируют широкую полосу, покрывающую УФ и синий диапазон спектра. Это характерно для алмазов Ib-типа [26]. Как сообщалось, центры окраски в алмазах связаны с дефектами их структуры $[15,26]$. В образцах, синтезированных методом НРНТ, доминирует дефект, связанный с наличием атомов азота [27]. В образцах присутствуют дефекты типов С, А, В и $\mathrm{N} 3$, связанные с агрегацией одиночных атомов азота в комплексы разного типа. При возбуждении лазером с длиной волны $266 \mathrm{~nm}$ при комнатной температуре образцы, кроме порошка $5 \mathrm{~nm}$, демонстрируют широкополосную люминесценцию в УФ-видимом диапазоне (рис. 7). Отсутствие люминесценции у образца $5 \mathrm{~nm}$, скорее всего, связано с самопоглощением фотонов аморфным углеродом, присутствующим в образце. Было замечено, что полоса излучения для каждого образца состоит из нескольких перекрывающихся полос. Измерения при комнатной температуре не позволяют точно определить положения и интенсивности каждой компоненты. Полоса излучения образца $500 \mathrm{~nm}$ центрирована на $450 \mathrm{~nm}$, образцов 1-2 и $100 \mu \mathrm{m}-$ на $531 \mathrm{~nm}$, алмазной пластины - на $498 \mathrm{~nm}$. Как было показано, образование дефектов зависит от температуры отжига в процессе синтеза $[28,29]$. Время затухания люминесценции представлено на рис. 8. Затухание измерялось при комнатной температуре и регистрировалось в максимуме полосы излучения. Было обнаружено, что люминесценция проявляет неоднозначное экспоненциальное поведение, что связано с излучением дефектов различного типа. Обычно наблюдается тенденция к тому, что время затухания уменьшается с увеличением размера алмаза, но это явление тесно связано с типом дефектов в структуре алмаза. 


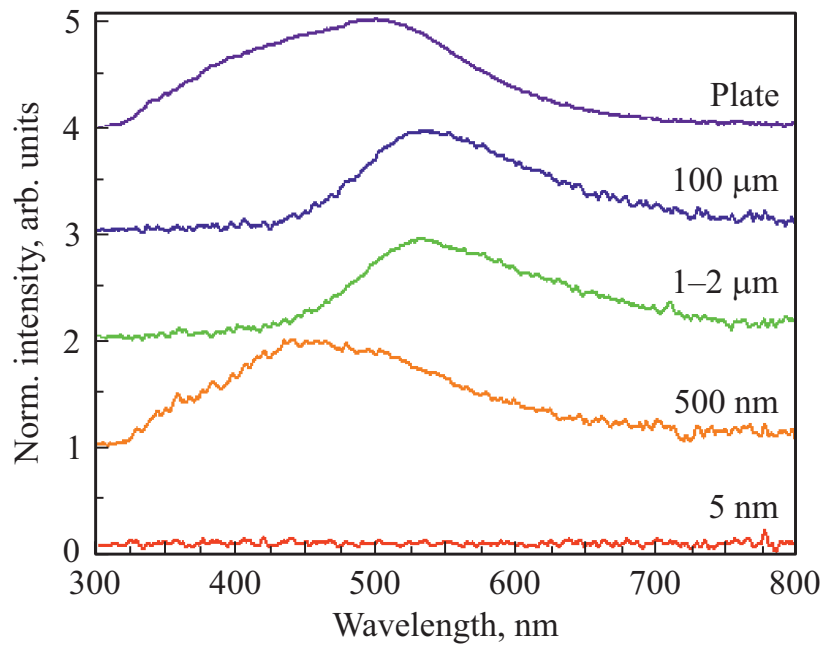

Рис. 7. Спектры люминесценции исследованных образцов при возбуждении диодным лазером с длиной волны $266 \mathrm{~nm}$.

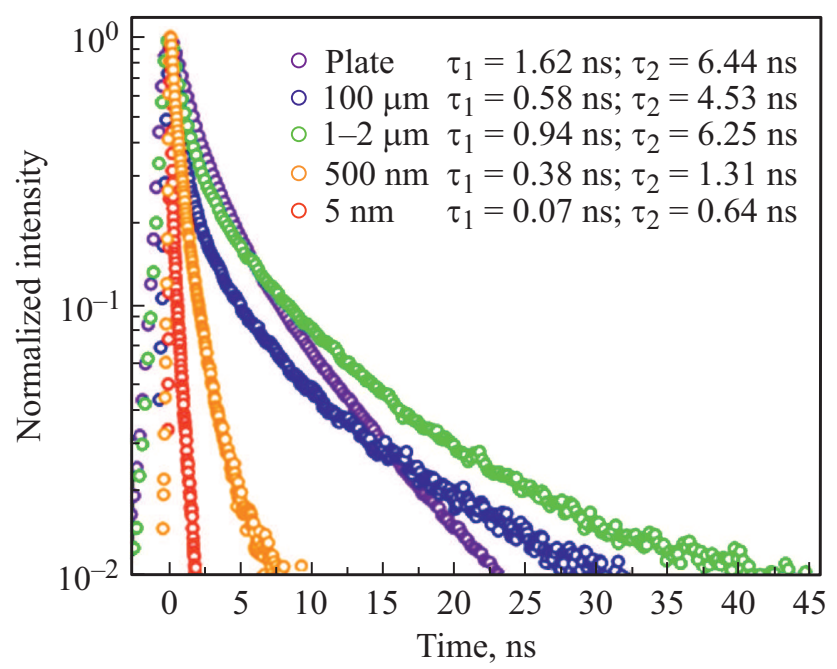

Рис. 8. Кривые затухания люминесценции исследованных образцов алмаза при возбуждении на длине волны $266 \mathrm{~nm}$, зарегистрированные в максимуме полос излучения (для образца $5 \mathrm{~nm}$ при $450 \mathrm{~nm})$.

\section{Выводы}

Эта работа дает анализ синтетических алмазов, проводя оценку спектров люминесценции на основе различных размеров зерен. Наши результаты подтверждают сильный эффект, связанный с размером микрокристаллитов алмаза. Цвет варьируется в каждом случае от зеленого, который может появиться из остаточного материала после синтеза, через белый, до серого результат дефектов на поверхности. Кристалличность образцов уменьшается вместе с размером образца. На более мелких алмазах первостепенное значение имеет вклад аморфного и $s p^{2}$-гибридизированного углерода у поверхности. На спектры комбинационного рассеяния света влияет структура и морфология частиц, так что полосы алмаза едва видны для наноалмазов. Это влияние проявляется также при измерении люминесценции: образец наименьшего размера имеет наименее заметные спектры люминесценции. В целом результаты демонстрируют влияние диаметра зерна и метода синтеза на расположение и свойства поверхностных атомов.

\section{Благодарности}

Авторы благодарят Эву Буковску за измерение рентгеновских дифрактограмм (XRD).

\section{Финансирование работы}

Работа финансировалась Национальным научным центром Польши в рамках гранта OPUS 15 (2018/29 / B / ST5 / 00819).

\section{Конфликт интересов}

Авторы заявляют об отсутствии конфликта интересов.

\section{Список литературы}

[1] G.P. Bulanova. J. Geochemical Explor., 53, 1 (1995).

[2] F. Nestola, C.A. Goodrich, M. Morana, A. Barbaro, R.S. Jakubek, O. Christ, F.E. Brenker, M.C. Domeneghetti, M.C. Dalconi, M. Alvaro, A.M. Fioretti, K.D. Litasov, M.D. Fries, M. Leoni, N.P.M. Casati, P. Jenniskens, M.H. Shaddad. Proc. Natl. Acad. Sci. U. S. A, 117, 25310 (2020).

[3] D.C. Kinsey. J. Br. Stud., 48, 391 (2009).

[4] H.T. Hall. Rev. Sci. Instrum., 31, 125 (1960).

[5] M. Schwander, K. Partes. Diam. Relat. Mater., 20, 1287 (2011).

[6] P.S. Decarli, J.C. Jamieson. Science, 133, 1821 (1961).

[7] V.Y. Dolmatov. Russ. J. Appl. Chem., 79, 1913 (2006).

[8] V.N. Mochalin, O. Shenderova, D. Ho, Y. Gogotsi. Nat. Nanotechnol., 7, 11 (2011).

[9] N. Nunn, M. Torelli, G. Mcguire, O. Shenderova. Curr. Opin. Solid State Mater. Sci., 21, 1 (2017).

[10] M.D. Torelli, N.A. Nunn, O.A. Shenderova. Small, 15, 1902151 (2019).

[11] K.N. Boldyrev, B.N. Mavrin, P.S. Sherin, M.N. Popova. J. Lumin., 193, 119 (2018).

[12] B.Z. Malkin, N.M. Abishev, E.I. Baibekov, D.S. Pytalev, K.N. Boldyrev, M.N. Popova, M. Bettinelli. Phys. Rev. B, 96, 1 (2017).

[13] E.A. Ekimov, S.G. Lyapin, K.N. Boldyrev, M.V. Kondrin, R. Khmelnitskiy, V.A. Gavva, T.V. Kotereva, M.N. Popova. JETP Lett., 102, 701 (2015).

[14] W. Strek, A. Olejniczak, R. Tomala, B. Cichy, A. Zhaludkevich, A. Konovalova, O. Ignatenko. Proc. SPIE, 10683, 1068307 (2018).

[15] J. Lindblom, J. Hölsö, H. Papunen, H. Häkkänen. Am. Mineral., 90, 428 (2005).

[16] T. Hainschwang. Gemstone Analysis by Spectroscopy, 3rd ed. (Elsevier Ltd., 2016).

[17] A.M. Zaitsev. Optical Properties of Diamond (Springer, Berlin, 2001). 
[18] K. Iakoubovskii, M.V. Baidakova, B.H. Wouters, A. Stesmans, G.J. Adriaenssens, A.Y. Vul', P.J. Grobet. Diam. Relat. Mater., 9, 861 (2000).

[19] R.A. Khmelnitsky, A.A. Gippius. Phase Transitions, 87, 175 (2014).

[20] A. Olejniczak, R. Tomala, B. Cichy, P. Głuchowski, M. Jakimów, A. Zięba, L. Kępiński, O. Ignatenko, W. Strék. Carbon N. Y., 146, 438 (2019).

[21] S.A. Solin, A.K. Ramdas. Phys. Rev. B, 1, 1687 (1970).

[22] G.J. Smith, J. Ellis, R. Moussaoui, C. Pardanaud, C. Martin, J. Achard, R. Issaoui, T. Gans, J.P. Dedrick, G. Cartry. J. Phys. D. Appl. Phys., 53, (2020).

[23] A.A. Khomich, R.A. Khmelnitsky, A.V. Khomich. Nanomaterials, 10, 1 (2020).

[24] O.N. Poklonskaya, A.A. Khomich. J. Appl. Spectrosc., 80, 715 (2013).

[25] M.A. Pimenta, G. Dresselhaus, M.S. Dresselhaus, L.G. Cancado, A. Jorio, R. Saito. Phys. Chem. Chem. Phys., 9, 1276 (2007).

[26] N.M. Kazuchits, M.S. Rusetsky, V.N. Kazuchits, A.M. Zaitsev. Diam. Relat. Mater., 64, 202 (2016).

[27] N. Chen, H. Ma, B. Yan, L. Chen, L. Chen, L. Guo, X. Miao, C. Fang, X. Jia. Cryst. Growth Des., 18, 3870 (2018).

[28] I.N. Kupriyanov, Y.N. Palyanov, A.A. Kalinin, V.S. Shatsky. Crystals, 10, 1 (2020).

[29] A.M. Wassell, C.D. Mc Guinness, C. Hodges, P.M.P. Lanigan, D. Fisher, P.M. Martineau, M.E. Newton, S.A. Lynch. Phys. Status Solidi Appl. Mater. Sci., 215, 1 (2018).

Перевод с английского К.Н. Болдырев 